\title{
Chinese students' decisions to undertake postgraduate study overseas
}

Purpose: This study surfaces themes which may influence Chinese students' decision making in relation to postgraduate study in international universities.

Design/ methodology/ approach: The study utilises a semi-structured qualitative interview methodology $(n=15)$.

Findings: The main findings are discussed according to the following themes: (i) financial and time costs; (ii) employment prospects; (iii) postgraduate education as a cultural adventure; (iv) linguistics; (v) visa issues; (vi) admissions; (vii) climate; (viii) influence of referents, and; (ix) academic image and reputation.

Research limitations/ Implications: The sample size is small, yet affords greater depth of data and discussion.

Practical Implications: The research offers practitioners in universities who are managing postgraduate recruitment of Chinese students, some greater understanding of the reasons behind prospective Chinese postgraduate students' choice; from which they can evaluate the effectiveness of their institutions' recruitment strategies.

Originality/Value:. Extant research has tended to report reasons why Chinese students study overseas, whereas this study offers deeper insight and exploration of the reasoning of Chinese international students in the postgraduate context. The research is of value given the importance of postgraduate Chinese students to international university recruitment.

Keywords: China, higher education, postgraduate, international student.

Paper Type: Research paper 


\section{Introduction}

Given the enormity of the Chinese population coupled with the country's fast paced economic growth, there are significant opportunities for international trade relationships. One such international trade relationship is in terms of Chinese young adult consumption of international higher education services. According to data from the Ministry of Education of the People's Republic of China, the number of Chinese students studying overseas surged from 179,800 in 2008 to 608,400 in 2017.Therefore China has been the most important source country for international students to English speaking countries like the UK, the US, and Australia in recent years. The focus of this paper is to understand what influences Chinese young adults in their consumption choices pertaining to international postgraduate study choices.

There is a need for research to understand what influences Chinese students to study overseas so that higher education institutions sustain and strengthen their competitive advantage. In addition, as domestic Chinese higher education expands and develops, there is a need for international higher education providers to understand the reasoning of Chinese students who wish to leave their home country and study in international universities.

The central research question that this study addresses is:

(1) What influences Chinese students' decisions to undertake postgraduate study overseas in international universities?

This research question grows out of what we would suggest that we do not quite yet know about higher education choice in the context of this study. Therefore to the 
authors' knowledge no other well disseminated study addressing this specific research question undertakes research based on a qualitative method in relation to postgraduate study, with a respondent sample not limited to specific subject areas, based on primary data collected from Chinese students with an intention to study overseas. This qualitative research seeks to build a deeper understanding, interpretation and discussion of drivers behind Chinese students' choice of international universities. This is in contrast to existing quantitative studies which tend to merely report incidence of factors, without any deeper exploration of what this means from the perception of students. In our study, all the respondents were interviewed at approximately the time of making decisions in relation to studying for an overseas postgraduate course; thereby enhancing the validity of this study.

The approach this paper takes is as follows. First the literature on student higher education choice and in particular the Chinese student context is reviewed. In this section, limitations of student choice studies are also discussed. Second the primary research objective is specified, and the methodology used to address it. Third the findings of the study are reported. Finally, the paper concludes by discussing how key findings link into and further debate on the nature of the prospective postgraduate Chinese student decision making, and the implications for higher education providers.

\section{Literature Review}

In the specific context of Chinese students who choose to study overseas various authors have illuminated push and pull factors leading to international higher education choices (Li and Bray, 2007; de Wit, 2008;Dimmock and Leong, 2010;Chan, 2012; James-MacEachern and Yun, 2017). Push factors according to Chan (2012) include factors such as perceived increased value of obtaining a foreign degree, and high levels 
of competitiveness for access to domestic university places. Pull factors are where host countries offer perceived superior conditions for study than domestic providers, for example in terms of quality of higher education provision, or macro-environmental factors. Dimmock and Leong (2010) examine the reasoning behind Chinese students' overseas study with a particular emphasis to Singapore. They contend that studying overseas is because of economic and demographic factors, and despite rapid domestic Chinese higher education expansion, there remains an inherent shortage of available places. However, Dimmock and Leong (2010, p.27) note that studying overseas can have significant risks such as 'language difficulties, different pedagogic traditions and expectations, life-style differences and culture shock'. They assert that push factors include limitations in respect of admission, teaching and learning, and societal culture, whilst pull factors include consideration of cost, quality and culture. They furthermore contend that a decision to study abroad is conditioned by the resilience of the individual student in terms of adaptation to differing learning and teaching, living environments and culture. The authors also articulate that a choice to study abroad is influenced by long term residence intentions post study (i.e. return home, remain in study destination, or intention to reside in a third country).

International mobility of students can be associated with gaining exposure to contrasting cultural environments between that of their home and host country ( $\mathrm{Gu}$ et al 2010; Chan, 2012; van Oorschot, 2014; Tran and Pham, 2016). However, research has shown that some Chinese students may face difficulties with linguistic and cultural adaptation whilst studying overseas (Tran and Pham, 2016). Despite such challenges, Guo et al (2013) note the necessity of English language development to enhance 
China's competitiveness. The authors suggest that English language skills enhance employment opportunities and afford greater financial security.

Gill (2007) conducted a qualitative study of Chinese students who choose to study at postgraduate level overseas. They find that students have some anxiety when first encountering higher education because of their lack of a-priori experience of British higher education and cultural norms. However over time, they adapt as a means to 'fit in' to the educational and cultural contexts, and in doing so develop a greater intercultural competence by interacting and building relationships; thereby reframing their own self identity.

Manns and Swift (2016) investigate the choices of Chinese higher education students in postgraduate business and management education. They propose a four stage sequential model (each stage has supported associated ranking factors listed in order of importance) which are: (i) country (i.e recommendations, social/cultural life, country attraction, country environment); (ii) programme (i.e recommendations, information, ranking/employability); (iii) university (i.e recommendations, university image, accommodation, facilities/location), and; (iv) city (i.e. recommendations, city location/ international environment, city attractions). Cao et al's (2016) quantitative study of Chinese students' international mobility reveals a number of factors that may influence their choice of overseas education such as: mobility cost, quality of international universities, future career prospects, financial support, economic indicators in host country, climate, environment, geographic distance, parental influence and language. Rudd et al (2012) adopt a qualitative design to surface themes that influence Chinese student choice processes when choosing a UK business school. From this study a significant number of qualitative themes emerge which include: (i) personal reasons (i.e western culture, advice from friends); (ii) country image; (iii) city effects (i.e cost of 
living, safety); (iv) institution image (i.e language support, information technology facilities, teaching) and; (iv) school image (i.e. teaching, buildings, placement opportunities).

James-MacEachern and Yun (2017) completed a comparative quantitative study of Chinese and other international undergraduate students at a small college in Canada. The most used sources of information for Chinese students were the university web site, educational recruitment agencies, the university's people/ alumni, teacher or careers counsellor from China, and friends and acquaintances. The most useful sources of information for Chinese students were university web sites, the university's people/ alumni, other internet sites, brochures/ pamphlets, host country government web site. The most important motivations of Chinese students to study at their chosen institution were environmental issues such as language, safety, affordability, opportunities to remain in country post graduation and educational facilities.

Ianneli and Huang (2014) argue that self-sponsored Chinese students are attracted to the UK in response to what they argue is 'revenue generation' policy (a theme echoed in Chan, 2012 and Haigh, 2008), whereby large numbers of non-EU full fee paying students are enrolled at UK universities, as well as contributing to economic growth via their living costs. In addition, they contend that the Chinese government have encouraged Chinese students to study overseas in order for them to offer enriched human capital necessary for Chinese future economic development when the Chinese students return. Ianneli and Huang (2014) then turn to the push factors driving increasing numbers of Chinese students studying overseas. These include: (i) entrance tests for access to domestic higher education; (ii) increased competition for Chinese higher education places, and; (iii) dissatisfaction with some aspects of Chinese higher education provision. 
There is a generic literature on drivers of student choice (e.g.; Manski and Wise, 1983; Kotler and Fox, 1995;Hossler et al, 1999; Cubillo et al, 2006; Shanka et al, 2006; Maringe and Carter, 2007; Vrontis et al, 2007;Simões and Soares, 2010;HemsleyBrown, 2012; Zheng, 2014; Hemsley-Brown and Oplatka, 2015; Ahmad et al, 2016; Alfattal, 2017). There have been models of student choice which are based on quantitative data. For example, Maringe's (2006) survey of domestic UK students arrives at a model comprising of factors affecting university choice (in rank order: programmes, price, place, prominence,promotion/prospectus, people) and factors affecting course choice (in rank order: career, ability, teacher advice, interest, staff profile, prestige, friends, career opportunities, parental advice, perceived ease of course). Basha et al's (2016) model comprises: (i) university level factors (i.e reputation, course suitability, teaching quality, cost, job prospects; (ii) programme mode, and; (iii) country of design. Briggs' (2006) models' found the importance of factors in rank order were: (i) Academic Reputation; (ii)Distance from home; (iii) location; (iv) student perception; (v) graduate employment prospects; (vi) social life; (vii) entrance requirements; (viii) teaching reputation; (ix) teaching staff quality; (x) information supplied by university, and (xi) research reputation. However a limitation of this model was that it was based on engineering and accounting students at universities in Scotland

Hemsley-Brown and Oplatka (2015) posit a two stage model based on student factors (e.g. demographics, socio-economic indicators, school performance, entry qualifications, reputation of institution) and student/institutional factors (e.g outcomes/ benefits, institutional characteristics and image, geography, information sources, price, reputation, ranking etc). However, a limitation of this model is that it is not based on primary data but rather a meta-analysis of varied studies. Moreover, Hemsley-Brown 
and Oplatka's (2016) model comprises: (i) personal and group characteristics (e.g demographics, social-economic characteristics, lifestyle achievement, cultural); (ii) attitude to institutional factors (information sources, reputation/ image, institutional characteristics, facilities, location, outcomes/benefits, price), and; (iii) type of institution chosen (e.g. ranking issues, type of institution, length of programme, and locational issues of university facilities). However it should be noted that this model is not specifically designed for international student choice, with only one variable denoting this at a latter stage of the model.

Vrontis' (2007) study of student decision making included variables such as: (i)Individual determinants-Consumer attributes/ demographic factors, and personal attributes (e.g class, self image, personality, benefits sought, lifestyle, educational aspirations, academic ability); (ii) environmental determinants (occupation, economic, cultural, grants, influencers/ media); (iii)higher education institutions characteristics (costs, financial aid, size, location, public or private sector, programme availability) and actions (recruitment, admissions policy, grants, communications) ,and; (iv)High School Characteristics (social composition, quality, curriculum), yet its weakness was that it was conceptual and claims to generalise for the wide context of developed countries. Maringe and Carter (2007) developed a model of student choice for African students in the UK. The model identifies: (i)push factors such as pollical, economic and home country capacity; (ii) key influencers to students; (iii) pull factors at country and institutional/ course/ programme level (e.g. quality issues, safety, ease of application/ availability, experience, post-degree progression, institutional teaching/ research profile, accommodation issues); (iii) risk and anxieties, and; (iv) experiential dissatisfiers . A limitation of this method is that it uses focus group data which means that students may not be willing to speak openly about these choice decisions in front of 
peers, and the data is reliant on accurately recalling influences some time after the decision.

Whilst there have been a number of studies on Chinese student decision making each one is significantly different from this study. For example, other studies focus on: (i) different countries (i.e Singapore, (Dimmock and Leong, 2010) and Canada (JamesMacEachern and Yun, 2017); (ii) undergraduate study decisions (e.g Cao et al, 2016, James-MacEachern and Yun, 2017); (iii)Business Schools (Manns and Swift, 2016; Rudd, 2012); (iv) descriptive statistics based on secondary quantitative data (i.e which type of university, degree choice, attainment etc) ( Ianneli and Huang,2016); (v) quantitative studies which tell us what factors lead to international choice (e.g.Cao, 2016; Manns and Swift, 2016), but have limitations in terms of deriving deeper meanings of why a student posits a response that can be uncovered in qualitative methods; (vi) sample on the basis of those students who are intending to study overseas and instead only measure general perceptions of academic mobility (leading to questions of validity given some of the sample would have no intention, or actual behaviour with regard to international student mobility (Cao et (2016)), or; (vii) collect data when students arrive to a country resulting in potential post-purchase evaluation and recall biases (e.g, Maringe and Carter, 2007)

\section{Method}

The datain this study was collected from 15 respondents at Xi'an University of Finance and Economics and Xi'an International Studies University. The students were final year undergraduate students who were at the point of considering where to study overseas for their postgraduate education. The sampling approach was influenced by Glaser and Strauss' (1967) 'theoretical sampling'. The semi -structured qualitative interviews were 
longer than many other typical qualitative studies; with interviews typically lasting between 2 hours, and 2 hours and 30 minutes. 13 of the interviews were conducted in Mandarin and 2 were conducted in English (as requested by the respondents who would like to take the chance to practice their English language skills). Data was collected in July 2011. All interviews were transcribed verbatim into English for the purposes of data analysis. This process generated around 260,000 words of raw data. Hence the data went through processes of open coding on transcripts, meta-coding, data matrix construction and data reduction (Miles and Huberman, 1994). This enabled the researchers to compare the data with extant literature to inform the theory development in this paper.

\section{Findings}

The paper will now discuss the main findings of the study according to the principal themes of: (i) financial and time costs; (ii) employment prospects; (iii) postgraduate education as a cultural adventure; (iv) linguistics; (v) visa issues; (vi) admissions; (vii) climate; (viii) influence of referents; (ix) academic image and reputation.

\section{Financial and Time Costs}

The primary data suggested that financial and time costs were key influencers in the decision for Chinese students to study abroad. The following transcript excerpt aptly demonstrates the financial and time costs issues considered:

'As you know, completing a master course in the UK requires only one year. I cannot only save the money but also the time for my future. In China, a master course requires three years. In the US or Australia, it requires two 
years or more. The UK has the shortest length of study. This means I can have the age advantage in my future work after graduation.'

Given the considerable cost of studying overseas the amount of parental financial support for overseas postgraduate study was a frequently recurring theme in the data. As one respondent stated:

'My parents can support me [with] money for my study abroad. What they can afford is approximate $\$ 28,000$ per year... That's not much if it is compared with other American universities. However, my parents cannot support me any more than that because I am not from a very rich family'.

\section{Employment Prospects}

From the data it was clear that Chinese students perceived an overseas postgraduate degree as a means to enhance their post-graduation employment prospects. Our study found that respondents who studied for postgraduate degrees outside China did so because of either the desire to boost their employability when they returned to China or in another foreign country. As one respondent stated:

'I have already found a company I can work for after I complete my study.

What I really need before going to work is having foreign experience and a foreign degree.'

To this end there were views expressed that the degree should be officially recognised in the global market, and back home in China. As one respondent stated: 
'I want to have a higher level qualification for my future career development. Simply speaking, it is for a good permanent job. Moreover, a foreign certificate is usually more competitive than a Chinese one [in the job market]. So, I decided to go abroad for further study.'

A minority of respondents were concerned about perceived opportunities to find a part time job whilst completing their postgraduate studies. As one respondent stated:

'I will find a part-time job when I am studying. I am not from a rich family. That's why I am now working hard to save money. I know the money I earned so far is ... trivial... I have eased my parents' burden to some extent'.

\section{Postgraduate Education as a Cultural Adventure}

Many students viewed the opportunity of studying overseas as a means to acquire foreign experience and seek adventure, whilst at the same time building knowledge allied to their study interests. Linked to this theme was a desire for some respondents to seek independence. As one respondent stated:

'I want to go for an environment for study with less Chinese people. I really want to experience British culture by myself... because it is my country [referring to China] and I have got used to the culture.'

There was however a view indicated that some students did not wish to study in institutions that had large numbers of Chinese students enrolled on to programmes of study. For example: 
'I don't want to go into an environment having too many Chinese. This is also a reason that I did not choose to study finance. There are too many Chinese students selecting the course of finance'

\section{Linguistics}

Many respondents stressed the desire to study in an English speaking country. This was inevitably because English was their second language, and some respondents perceived postgraduate study in an English speaking country as an opportunity to improve their language skills. As a respondent claimed:

'I'd like to enhance my English ability. This is more important than learning a third language. Therefore, it must be an English speaking country ....That means the options can be the UK, the US, Canada, Australia, Ireland, and New Zealand.'

However, an underlying concern for some respondents was their ability to understand regional accents; particularly in some regions of the UK.

\section{Visa Issues}

It was also apparent from the data that the time and perceived ease of which it took for applying to a foreign university and obtaining a student visa was an important issue for some students choosing to study in the UK. The ease of obtaining a student visa was a particular issue mentioned by Chinese students who wished to study in the UK. As one respondent stated: 
'I did not have much time for ....applying [to an] American university and the student visa for the US. Applying [for] a British university and student visa is simpler. Additionally, I would only need to prepare [for] one English test; namely the IELTS.'

For students who wished to study overseas but in non UK universities, a minority of students were concerned with their ability to gain an employment visa. There were no potential UK applicants who expressed a desire to obtain a work visa whilst studying for a UK degree.

\section{Admissions}

It was noticeable from the data that the respondents' perceived likelihood of successful admission to their preferred overseas university was a key influencer in the postgraduate application process. An interesting driver which led students to seek study opportunities overseas was the perceived intensity of competition for places in the domestic Chinese higher education sector. As a respondent stated:

'I decided to go abroad because there are not many places available in Chinese universities [which] cater for my course which is English'

\section{Climate}

When making choices about overseas postgraduate higher education, Chinese students were very often concerned with issues of the natural environment and the weather. Climatic issues were not however solely concerned with physical conditions. For example, a consideration was perceptions of safety and the affluence of the host country. The fear of crime is seen in the following data: 
'The country for my higher education must be more developed than China and have [a] better natural environment and safety climate than China. If not, I['d] rather stay in China.'

'At the time I apply [to] a British university, it was reported that there was an international student murdered. She [referring to her mother] really did not want me to go to the UK.'

'Japan is not bad, but the natural disasters take place too often. For the safety reason, I don't want to go there.'

\section{Influence of Referents}

The primary data suggests that referents are important influencers in the foreign higher education choices of Chinese students. Key to this is the parental and familial influence because of the financial support which they can provide. Another key influencer was that of friends in terms of their suggestions for postgraduate study overseas. As a respondent adds:

'The reason I chose Canada is largely due to my friend who had been in Toronto for many years. Everything seems terrific according to what she said. In addition, she promised to take care of me once I arrived there.'

In addition, the data suggests that education agents can have an effect on international study destination. The influence of Chinese undergraduate tutors can also have an impact on study destination choice for some students.

\section{Academic Image and Reputation}

The primary data suggests academic reputation of the chosen country and university 
were important influencers in the postgraduate study choices of Chinese students wishing to continue their studies overseas.

For example, a respondent stated:

'The quality of education can be higher in foreign countries with [a] prestigious education image. This is why I decided to go abroad.'

\section{Discussion and Implications}

Consumer research studies have reported that Chinese consumers place considerable emphasis on thrift and frugality in their consumption behaviour (Doran, 2002; Wang et al, 2008). Our study shows that such characteristics impact on international study choice. Whilst extant literature has indicated cost being important in decision making this has been in generic terms; research has not identified that length of postgraduate taught degree programmes in respective countries as being a key influencer of decision making. Hence this research furthers debate about cost in that it becomes a trade off between the inter-linked dimensions of finance and time; albeit one which is now linked to the quality assurance landscape architecture of specific countries. For example, given the shorter postgraduate taught registration period for UK degrees than many of its international competitors, the UK may have a competitive advantage in recruiting and retaining Chinese students as many perceive the choice of the UK as less financial and time intensive for postgraduate study, than many other international competitors. This could be a key marketing asset for UK higher education institutions which should be emphasized in marketing communications. The shorter period of study for taught programmes than many international competitors (especially continental EU countries) may however deter some Chinese students who may wish to have a longer period to 
settle in to the higher education culture; afforded by countries with longer postgraduate taught programmes.

Whilst enhancement of employment prospects has been a factor identified in quantitative research, there has been less of a understanding that a foreign qualification can render a symbolic differential advantage to students when they return to China to seek employment. This may be especially the case for countries such as the US, UK, Canada and Australia which have a long established and internationally respected higher education culture. Indeed such 'Westernised' systems of education may yield in the minds of potential Chinese students indicators of brand heritage, quality and reputation emblematic of such countries. In particular certain countries carry with them a positive country of origin effect, which enables the debate to move beyond the lens of image and reputation which are alluded to by several conceptual studies (e.g. Mazzarol, 1998; Hemsley-Brown and Oplatka, 2006; Chen 2008; Hemsley-Brown, 2012;

Hemsley-Brown and Oplatka, 2016). Our study further points to this new emerging research area in relation to the increasing recruitment influence of country of origin effects in Chinese students' choice of higher education (Zhu, 2014; Basha et al, 2016).

Alternatively Liang and $\mathrm{He}$ (2012) stress the role of a 'best seller' impact on consumption. This translated to university choice means that where other Chinese consumers have experience of a particular university or university system, this may yield an advantage to the established and more popular higher education markets. This reinforces the influence of referents on Chinese consumer decision making (interpersonal and familial e.g. Chen 2008; Abubakar et al, 2010; Ahmad et al, 2016; James-MacEachern and Yun, 2017). More specifically Wilkins and Huisman (2011, p.63) argued that 'the country and institutional choices of international students are greatly influenced by recommendations they receive from others who have experience 
of higher education overseas'. Whilst previous research has noted the impacts of referents, our study enables us to identify some specific categories of referents including interestingly, an in-country peer influencer as a kind of experiential cultural safety net for potential students. The data shows that Chinese students are sometimes nervous about such an exposure to differing cultural consumption experiences. A good example of this tension is in relation to foreign language competence with some students viewing it as a cultural opportunity whilst others a cultural challenge.Conversely our study exposes that some Chinese students may be attempting to culturally distance themselves from some institutions and programmes that have higher levels of Chinese students. This leads to new knowledge in relation to seeking exposure to study based upon the notion of seeking authenticity of cultural experiences in their chosen country, and resultant possible perceived competitive advantage in the Chinese labour market postgraduation.

A somewhat novel finding from the study is the concern about the climate of the country with which Chinese students wish to study in. By this, students not only mean the natural environment and potential extreme weather events, but also perceptions of crime and safety. It is important for student retention that Chinese students are supported in this cultural adaptation either through university interventions (i.e. language and academic training top up support, university established student societies, accommodation support, advice on safety and security), and /or informal peer groups of current students/ alumni. Moreover they were very often concerned with issues of the natural environment, the weather, and safety. This may point to an increasing concern amongst Chinese consumers in relation to sustainability issues, or an elevated concern towards consumer well being and safety 
As Chinese students are unlikely to be entitled to any financial support that is available to Home students, it is necessary to appreciate that in many cases that Chinese students will be funded by parents. The focus of university higher education recruitment marketing materials is aimed at the potential students. This is appropriate as clearly the student is the main participant in the higher education exchange. However, where higher education institutions should consider strengthening its marketing communications is at specifically adapted materials for parents. This is important and neglected as in many cases parents are a key decision making influencer in the postgraduate higher education choices of their children, since they often fund it. It should be recognised that many potential Chinese students' parents will have not experienced international higher education, and yet they are being asked to make significant financial sacrifices. Marketing materials and perhaps university led support functions (i.e. dedicated Mandarin speaking university representatives being available for consultation with parents across a range of communication channels) may assist and offer assurance to Chinese parents about their funding decisions. Furthermore, it should be recognised that friends of potential Chinese students who have studied at a particular institution may be important influencers for future potential students; therefore universities should develop relationship marketing approaches with alumni in order to promote positive word of mouth with potential applicants.

Many Chinese students wish to participate in overseas higher education in order to enrich their employment prospects when they return to China. They hope recruitment to a prestigious overseas institution will help them gain a competitive advantage over their peers in an increasingly competitive domestic Chinese labour market. Hence,a postgraduate degree from a reputable institution can be viewed as an important competitive edge for Chinese students. However, some students may wish to gain 
international employment experience either in a part time capacity whilst studying, or full time for a period after graduation. However, the data in this study provides little evidence to suggest that Chinese students wish to typically work in the UK. This is somewhat a contrasting finding to the Cheung and $\mathrm{Xu}$ (2015) US study which finds less of an intention amongst some Chinese students to return to China post study (i.e 20\% very unlikely or unlikely to return, and around one third unsure). Our study finds limited evidence to support Chan's (2012) concern that there is a risk of a 'brain drain' from China, as students originally from China choose to study overseas for their postgraduate education but fail to return from the host country.According to the National Bureau of Statistics of China from 1978 to 2017, 3,132,000 students chose to come back to China after graduation which accounted $83.73 \%$ of the total number.

The findings of this study can enable the Chinese government to better understand what influences more and more students' choices. Studying abroad cannot only strengthen China's cultural communication with other countries but also contribute to the nation's long-term development. It is clear that the demand for higher education in China outstrips supply, and so there are opportunities for international institutions to meet some of this demand with increased student recruitment. However, it should be noted that the Chinese higher education sector is rapidly expanding and that in the longer term net outflows of Chinese students may decrease as domestic provision expands. However, in the meantime international institutions should (perhaps through reputable agents) proactively identify and target cities and regions within China that have the biggest deficit of supply of domestic higher education places. In particular, the supply of postgraduate education opportunities in China may be significantly less than required for a longer period of time as the country addresses its undergraduate educational needs. The study advances knowledge in that it exposes that study overseas 
$\overline{\text { may not be in some cases a fully voluntary choice but rather a choice which is impacted }}$ by perceived or real limitations on access to postgraduate domestic education.

English speaking countries also have a competitive advantage over many other countries as Chinese students may view such countries as having a rich culture which they wish to participate in. Marketing recruitment communications by institutions should therefore communicate relevant aspects of cultural heritage that students may be able to engage with by studying at their institution. Moreover, as Chinese students often learn English as part of their schooling, English speaking countries have an advantage in recruiting Chinese students over non- English speaking countries. It should however be noted that there is a growing incidence of non-English speaking institutions offering English language taught programmes. This may reduce English speaking countries' market share in the medium to longer term, although English speaking countries still have an advantage as Chinese students may still be nervous about residing in a country, where outside of the university environment a non-English language dominates which they cannot engage with. Hence English speaking countries should emphasize that the total experience from entry and to exit to the country will be conducted in English; and hence there is no need for proficiency in a third language. Whilst English language issues have been well rehearsed in the extant literature, there has been limited recognition of how regional accents and dialects may condition applications from Chinese students, as identified in our study.

In summary this paper has discussed some core qualitative themes pertaining to Chinese consumer choice of international postgraduate higher education. Clearly the Chinese student postgraduate higher education market is of significant importance, and will remain so in future for both higher education providers and economies. This research furthers the cause of qualitative methods in understanding the reasons 
whyChinese international students make the international study choices that they do. It moves from beyond specifying on what basis decisions are made, to why the decision is made and locates this into some wider educational debates about the topic. 


\section{References}

Abubakar, B., Shanka, T. \& Muuka, G. N. (2010), Tertiary education: an investigation of location selection criteria and preferences by international students- the case of two Australian universities, Journal of Marketing for Higher Education, Vol. 20, No. 1, pp. 49-68.

Ahmad, S.Z., Buchanan, F.R. and Ahmad,N. (2016), “Examination of students' selection criteria for international education", International Journal of Educational Management, Vol. 30, No. 6,pp.1088-1103.

Alfattal, E. (2017), “International students' college choice is different!”, International Journal of Educational Management, Vol. 31, No.7, pp.930-943.

Basha, N.K, Sweeney, J. C and Soutar, G. N. (2016), “International students' university preferences: how different are Malaysian and Chinese students?", International Journal of Educational Management, Vol.30, No. 2, pp. 197-210.

Briggs, S. (2006) "An exploratory study of the factors influencing undergraduate student choice: The case of higher education in Scotland", Studies in Higher Education, $31(6)$, pp. 705-722.

Cao, C., Zhu, C. and Meng, Q. (2016),“A Survey of the influencing factors for international academic mobility of Chinese university students", Higher Education Quarterly, Vol. 70, No. 2, pp. 200-220

Chan, S. J. (2012), “Shifting patterns of student mobility in Asia”, Higher Education Policy, Vol. 25, No. 2, pp. 207-224

Chen, L. H. (2008), “Internationalization or international marketing? Two frameworks for understanding international students' choice of Canadian Universities”,Journal of Marketing for Higher Education, Vol.18, No. 1, pp. 1-33. 
Cheung, A.C.K and Xu. L.(2015), "To return or not to return: examining the return intentions of mainland Chinese students studying at elite universities in the United States”, Studies in Higher Education,Vol.40, No. 9,pp.1605-1624.

Cubillo, J. M., Sánchez, J. and Cervino, J. (2006), “International students’ decisionmaking process", International Journal of Educational Management, Vol. 20,No. 2, pp. 101-115.

de Wit, H (2008), “Changing dynamics in international student circulation: Meanings, push and pull factors trends and data", In de Wit, H., Agarwal, P., Said, M. E., Sehoole, M. T., and Sirozi, M.(Eds.)“ The Dynamics of International Student Circulation in a Global Context, Rotterdam, the Netherlands, Sense Publications, pp. 15-45.

Dimmock, C. and Leong, J. O. S. (2010), “Studying overseas: mainland Chinese students in Singapore", Compare: A Journal of Comparative and International Education, Vol. 40, No. 1, pp. 25-42.

Doran, K.B. (2002),"Lessons learned in cross-cultural research of Chinese and North American consumers", Journal of Business Research, Vol. 55, No. 10, pp. 823-829.

Gill, S. (2007),“Overseas students’ intercultural adaptation as intercultural learning: a transformative framework", Compare: A Journal of Comparative and International Education, Vol. 37, No. 2, pp. 167-183.

Glaser, B. G. and Strauss, A.L. (1967),Discovery of Grounded Theory: Strategies for Qualitative Research, Aldine, London.

Gu, Q., Schweisfurth, M.and Day, C. (2010),“Learning and growing in a 'foreign' context: Intercultural experiences of international students", Compare: A Journal of Comparative and International Education, Vol. 40, No. 1, pp. 7-23. 
Guo, S., Guo, Y., Beckett, G., Li, Q.and Guo, L.(2013),“Changes in Chinese education under globalisation and market economy: emerging issues and debates", Compare: A Journal of Comparative and International Education, Vol. 43, No. 2, pp.244-264. Haigh, M. (2008),“Internationalisation: planetary citizenship and Higher Education Inc.”, Compare: A Journal of Comparative and International Education, Vol. 38, No. 4, pp. $427-440$

Hemsley-Brown, J. (2012), “The best education in the world: reality, repetition or cliché? International students' reasons for choosing an English university”, Studies in Higher Education, Vol. 37, No. 8, pp. 1005-1022

Hemsley-Brown, J. and Oplatka, I. (2006),"Universities in a competitive global marketplace: a systematic review of the literature on higher education marketing", International Journal of Public Sector Management, Vol. 19, No. 4, pp. 316-338. Hemsley-Brown, J. and Oplatka, I. (2015), 'University choice: what do we know, what don't we know and what do we still need to find out", International Journal of Educational Management, Vol. 29, No. 3, pp. 254-274.

Hemsley-Brown, J. and Oplatka, I. (2016),Higher education consumer choice, Basingstoke, Palgrave Macmillan.

Hossler, D., Schmit, J. and Vesper, N. (1999),Going to College: how social, economic and educational factors influence the decisions students make, John Hopkins University Press,Baltimore, USA Iannelli, C., and Huang, J. (2014), "Trends in participation and attainment of Chinese students in UK higher education", Studies in Higher Education, Vol. 39, No. 5, pp. 805822. 
James-MacEachern, M., and Yun, D. (2017), "Exploring factors influencing international students' decision to choose a higher education institution, International Journal of Educational Management, Vol. 31, No. 3, pp. 343-363.

Kotler, P. and Fox, K. (1995),Strategic Marketing for Educational Institutions. $2^{\text {nd }}$ ed. Pearson Education, New Jersey, USA.

Li, M. and Bray, M. (2007), “Cross-border flows of students for higher education: Pushpull factors and motivations of mainland Chinese students in Hong Kong and Macau", Higher Education, Vol. 53, No. 6, pp. 791- 818.

Liang, B. and He, Y. (2012),"The effect of culture on consumer choice: the need for conformity vs. the need for uniqueness", International Journal of Consumer Studies, Vol. 36, No. 3, pp. 352-359.

Manns, Y. and Swift, J. (2016), “Chinese postgraduate choices when considering a UK business and management programme", Higher Education Quarterly, Vol. 70, No. 1, pp. $3-23$.

Manski, C. F. and Wise, D. A. (1983), College Choice in America, Harvard University Press Cambridge, UK

Maringe, F. (2006), "University and course choice: Implications for positioning, recruitment and marketing", International Journal of Educational Management, Vol. 20 No: 6, pp.466-479.

Maringe, F. and Carter, S. (2007), “International students' motivations for studying in UK HE: Insights into choice and decision making of African students", International Journal of Educational Management, Vol. 21, No. 6, pp. 459-475.

Mazzarol, T. (1998), “Critical success factors for international education marketing”, International Journal of Educational Management, Vol. 12, No. 4, pp. 163-175. 
Miles, M. B. and Huberman, A. M. (1994),Qualitative data analysis: an expanded sourcebook. $2^{\text {nd }}$ ed., Sage, London, UK.

Rudd, B., Djafarova, E. and Waring, T. (2012),“Chinese students' decision-making process: A case of a Business School in the UK", The International Journal of Management Education, Vol. 10, No. 2, pp. 129-138.

Shanka, T., Quintal, V., and Taylor, R. (2006), "Factors influencing international students' choice of an education destination- A correspondence analysis", Journal of Marketing for Higher Education, Vol. 15, No. 2, pp. 31-46.

Simões, C. and Soares, A. M. (2010),“Applying to higher education: information sources and choice factors", Studies in Higher Education, Vol. 35, No. 4, pp. 371-389. Tran, L.T. and Pham, L. (2016), “International students in transnational mobility: Intercultural connectedness with domestic and international peers, institutions and the wider community", Compare: A Journal of Comparative and International Education, Vol. 46, No.4, pp. 560-581.

van Oorschot, I. (2014),“Negotiating knowledges abroad: non-Western students and the global mobility of knowledge", Compare: A Journal of Comparative and International Education, Vol. 44, No. 6, pp. 895-915.

Vrontis, D., A. Thrassou and Melanthiou, Y. (2007),“'A contemporary higher education student-choice model for developed countries", Journal of Business Research, Vol. 60, No. 9, pp. 979-989.

Wang. G., Dou, W. and Zhou, N. (2008),“Consumption attitudes and adoption of new consumer products: a contingency approach”, European Journal of Marketing, Vol. 42, No. $1 / 2$, pp. $238-254$. 
Wilkins, S. and Huisman, J. (2011), “International student destination choice: The influence of home campus experience on the decision to consider branch campuses", Journal of Marketing for Higher Education, Vol. 21, No. 1, pp. 61-83.

Zheng, P. (2014),“Antecedents to international student inflows to UK higher education: a comparative analysis", Journal of Business Research, Vol. 67, No. 2, pp. 136-143. Zhu, L. (2014), “Country of Origin Influence on Service Evaluation: An insight into Chinese Students' Choice of British Higher Education", Unpublished PhD Thesis, University of Salford. 